\title{
Branch Updates
}

\section{Sara Baird}

\section{President, NS/PEI Branch Greetings from the East Coast!}

We are pleased to announce the Government of Nova Scotia has proclaimed the Safe Body Art Act, and it will come into effect on February 1, 2019. Many members of our Branch have worked extremely hard to ensure we, as Public Health Professionals, continue to keep Nova Scotians safe. As a Branch, we couldn't be prouder!

We welcome some new members to our Executive after an unconventional yet effective AGM on February 7, 2018. Jillian LaVatte has filled the long-time vacant Cape Breton Councilor position. We also welcome Tanya O'Brien as PEI Councilor; this is bittersweet as we must say "see you later" to a very dedicated member, Kelly Hughes.

I want to thank all our members and Executive for their continued support and wish you all the best.

\section{Kevin Kapell President, CIPHI Saskatchewan Branch Greetings from the Saskatchewan Branch!}

The Branch Executive is busy preparing for some upcoming face-to-face meetings and we have been busy with teleconference meetings as we plan our 2018 Professional Education and
Development Seminar. Tentatively, it appears it will be going ahead later in the fall of 2018. The Executive has also been busy continuing with an extensive policy review that will see many of our current polices being updated and will see the creation of some new policies that will assist with day to day branch business.

As many of you are aware, CIPHI National will be hosting the Annual Educational Conference from September 17-19, 2018 in Saskatoon, SK. Our members are looking forward to welcoming our colleagues from across the country to Saskatchewan in the fall. Saskatoon is a beautiful city that has a lot to offer visitors, and it will be a great time of the year to visit. If you have never been to Saskatchewan, have not been here in a while, or are one of our many expats, I encourage you to make plans to attend what I am sure will be a great event in a wonderful city.

Saskatchewan continues down the path of transitioning from 12 health authorities into one provincial health authority. As with any change, there is some apprehension among health care staff across the province including our provincially employed CIPHI members. To date, the changes have not had a large, direct impact on our members. Our Branch will continue to monitor these changes and will be there to advocate on behalf of our members if the need arises.

For more on our Branch's activities and goings on in Saskatchewan, please check out our newsletter the CIPHI Observer at http://www.ciphi-sk.ca/archives/date/2018. 